\title{
The association between fever in the first year of life and atopy in children with or without family history of atopic disease
}

\author{
Susy P. Wihadi, Budi Setiabudiawan, Cissy B. Kartasasmita
}

\begin{abstract}
Background The role of repeated infection in early life in the development of childhood atopy is still controversy. Fever in the first year of life which is frequently associated with infections might decrease atopy.

Objective The aim of this study was to investigate the association between fever in the first year of life and atopy in children.

Methods This was an observational clinical epidemiology study performed at Puskesmas Garuda, Padasuka, and Babakan Sari, Bandung, from January to March 2006. From 749 children, we randomly chose 150 subjects each from group with and without family history of atopic disease. Skin prick test and measurement of total serum immunoglobulin (Ig) E were performed on each children. Atopy was defined as the skin prick test result was positive to $>1$ allergen. The number of fever episodes in the first year of life was based on parents report. The relationship between fever and atopy was analyzed using Mantel Haenszel.

Results From 284 subjects, atopy was found in $28.2 \%$ of children, of which $32.4 \%$ with and $23.9 \%$ without a family history of atopic disease. Generally there was no significant association between fever and atopy. There was only decreased odds ratio with increased fever episodes and trend analysis showed this decrease was significant $(\mathrm{P}=0.01)$. The significant association between fever and atopy were found only in group without family history of atopic disease $(\mathrm{P}=0.03, \mathrm{OR}=0.43$, CI $95 \% 0.18 ; 1.01)$.

Conclusion There is a relationship between fever and atopy in children without family history of atopic disease. [Paediatr Indones 2007;47:65-70].
\end{abstract}

Keywords: atopy, fever, family history of atopic disease
I $\mathrm{n}$ the last three decades, the prevalence of asthma and atopic disease is increasing worldwide including in Indonesia. ${ }^{1,2}$ In 1995 the prevalence of wheezing in Indonesian children aged 12-13 years old is $2.1 \%$ and in 2003 became $5.2 \%{ }^{2,3}$ This trend is consistent in all population which have different lifestyle and ethnic. ${ }^{1}$ It has been suggested that this is the result of lower exposure to infection as consequences of declining family size, improved hygiene, and vaccination programmes. ${ }^{4,5}$ Immunological data showed that decreased exposure to infectious agents and endotoxin in early childhood can produce Th1/Th2 immune response imbalance. Exposure to bacterial and viral infections, selectively enhances differentiation of $\mathrm{T}$ helper cells to the Th1 subtype results in suppression of the Th2 subtype which is implicated in mediated allergy. ${ }^{6}$ The prevalence of atopy was found to be lower among children from large families, $4,5,7,8$ children attending daycare centre,, 9 exposed to measles, ${ }^{10,11}$ and nonwheezing lower respiratory tract illness ${ }^{12}$ in early life. In contrast,

From The Department of Child Health, Medical School, Padjadjaran University, Hasan Sadikin, General Hospital Bandung.

Reprint request to: Susy P. Wihadi, MD, Department of Child Health, Medical School, Padjadjaran University/ Hasan Sadikin General Hospital, Bandung. Jl. Pasteur No.38. Tel. 62-22-2034426. Fax. 62-22-2035957. 
other epidemiological studies failed to reveal the protective effect of infection in early life to atopy. ${ }^{13-17}$ Therefore the role of repeated infections in early life in the development of childhood atopy is still inconclusive.

Fever is frequently associated with infection in the first year of life. ${ }^{18}$ Few studies showed that the risk of being atopic was inversely related to the number of fever episodes. ${ }^{19-21}$ The aim of this study was to find out the association between fever and atopy and to investigate the effect of repeated fever episodes during the first year of life to atopy in children with or without family history of atopic disease.

\section{Methods}

This was an observational clinical epidemiology and part of "Prevalence and Identification of Allergic Risk Factor in the First Two Years of Life Study", performed at Puskesmas Babakan Sari, Padasuka, and Garuda in Bandung. This study consisted of three phases, phase I was community survey between May-August 2004. The parents of eligible children had consented to enroll their children. Inclusion criteria were children enrolled in phase I "Prevalence and Identification of Allergic Risk Factor in the First Two Years of Life" study and were physically healthy. Exclusion criteria were using first generation antihistamines for 24 to 72 hours prior to testing, non-sedating antihistamines for up to one week, regular administration of potent topical corticosteroids for two to three weeks prior to testing, or the parents could not mention the number of fever episodes in the first year of life of the child, or the child was moving out. Of 800 children, only 749 who were eligible to continue to the next phase, consisted of 204 children with family history of atopic disease and 545 without. Subjects of this study were randomized by computer from both groups; each group consisted of 150 children.

Information regarding fever was obtained from parents' anamnesis, taken from phase I questionnaire by the following questions: 1) How many fever episodes did your child have during the first 12 months of life?; 2) Did your child diagnosed by a doctor that he/she were having a fever?

Skin prick test (SPT) was performed in the volar aspect of the forearm and the skin must be free of eczema and wounds. The allergens were Blomia tropicalis, Dermatophagoides pteronyssinus, peanut, cat dander, cow's milk, white egg, soy, and cockroach. Histamine was used as positive control and saline as negative control. Children with a weal reaction of $\geq 3$ $\mathrm{mm}$ after subtraction of the reaction to negative control to one or more allergen tested were considered positive. Measurement of total serum IgE was done using ECLIA methods to determine the total serum and plasma IgE quantitatively. IgE cut-off point for age 1-3 years old was $60 \mathrm{IU} / \mathrm{mL}$.

This study has been approved by Medical Research Ethical Committee, Medical School, Padjadjaran University, Hasan Sadikin General Hospital Bandung.

Chi square test was used to test the nominal differences; unpaired t test or Mann-Whitney test were used to compare the continuous variable; odds ratio $(\mathrm{OR})$ was used to assess the risk of atopy with repeated fever episodes; Mantel Haenszel statistics was used to analyse the OR trend between groups.

\section{Results}

From 749 children enrolled in phase I, 300 were selected randomly; consisted of 150 children with family history of atopic disease and 150 without. Nine children were unavailable as the parents of nine children refused to continue this study; finally the number of eligible children were 284 (94.7\%) consisted of 130 (45.8\%) boys and 154 (54.2\%) girls. Based on the atopic disease history in the family, there were 142 (50\%) children with family history of atopic disease and 142 (50\%) without. The baseline characteristics of the children were not significantly different between both groups (Table 1).

Table 1. Baseline characteristics of the subjects

\begin{tabular}{lccc} 
Characteristics & \multicolumn{2}{c}{$\begin{array}{c}\text { Family history of atopic disease } \\
(+)\end{array}$} & $\begin{array}{c}\mathrm{P} \\
\text { value }\end{array}$ \\
\hline Sex & & & \\
$\quad$ Male & $64(44.8 \%)$ & $66(46.5 \%)$ & 0.770 \\
$\quad$ Female & $79(55.2 \%)$ & $76(53.5 \%)$ & \\
$\begin{array}{l}\text { Age of children (mo) } \\
\text { X (SB) }\end{array}$ & $36.39(1.75)$ & $36.15(1.83)$ & 0.257 \\
$\quad$ Range & $32.1-40.5$ & $32.5-40.2$ & \\
Nutritional status & & & \\
$\quad$ Underweight & $32(22.4 \%)$ & $39(27.5 \%)$ & 0.993 \\
$\quad$ Normal & $108(75.5 \%)$ & $101(71.1 \%)$ & \\
$\quad$ Overweight & $3(2.1 \%)$ & $2(1.4 \%)$ & \\
\hline
\end{tabular}


Susy P Wihadi et al: Fever and atopy in association with family history of atopic disease

Atopy

Of 284 subjects, 80 (28.2\%) children showed positive SPT (atopy) and 204 (71.8\%) negative (nonatopy). Atopy tendency in children with family history of atopic disease were more $(32.4 \%)$ than that in the group without family history of atopic disease (23.9\%), but this difference was not statistically significant $(\mathrm{P}=0.113)$ (data not shown)

\section{Fever episodes}

From 284 children, there were 1,122 fever episodes in the first year of life, 576 (51\%) affecting children with family history of atopic disease and 546 (49\%) affecting children without family history of atopic disease group. Mean of fever episodes were 4.05 and 3.85 per children respectively for children with and without family history of atopic disease. There were no statistical differences between the two groups $(\mathrm{P}=0.364)$. Fifteen of 284 children $(15 \%)$ did not experience any fever in their first year of life, seven (2\%) were children with family history of atopic disease, and eight (3\%) children were from family without history of atopic disease. Fever episodes in the first year of life were summarized in Figure 1.

\section{Association between fever episodes in the first year of life and atopy}

Generally there was no statistically significant association between fever episodes in the first year of

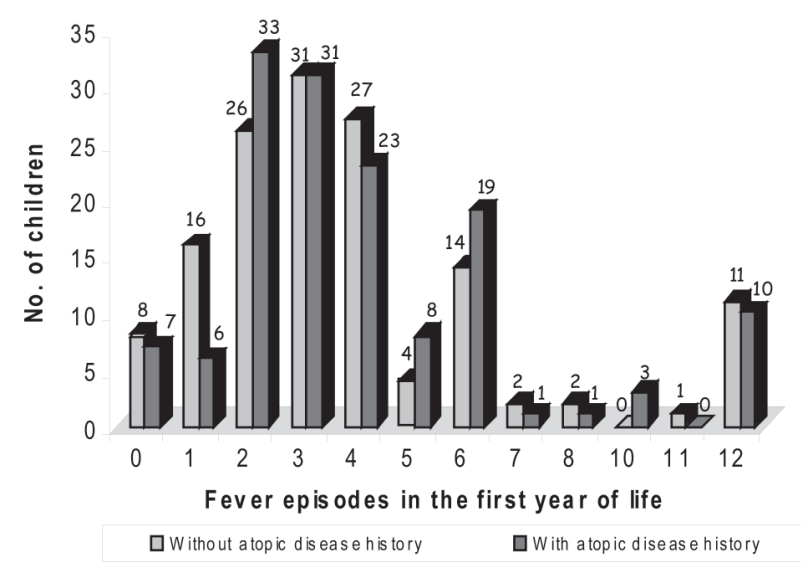

Figure 1. Fever episodes in the first year of life based on the family history of atopic disease life and atopy, but there was a decrease odds ratio as fever episodes increase. This decrease was analyzed using Mantel Haenszel and was statistically significant $(\mathrm{P}=0.010)$ (Table 2).

Table 2. Chi square test result between fever episodes and atopy

\begin{tabular}{ccccccc}
\hline $\begin{array}{c}\text { Fever } \\
\text { Episodes }\end{array}$ & Atopy & $\begin{array}{c}\text { Non } \\
\text { atopy }\end{array}$ & $\mathrm{P}$ & OR & Cl 95\% & \\
\hline$<1$ & 4 & 11 & 0.8 & & & \\
$>1$ & 76 & 193 & 94 & 0.92 & $0.24 ; 3.27$ & \\
$<2$ & 10 & 27 & 0.8 & & & \\
$>2$ & 7 & 177 & 68 & 0.94 & $0.40 ; 2.15$ & \\
$<3$ & 26 & 70 & 0.7 & & & $\mathrm{MH}^{*} \mathrm{OR}^{\# !}: 0.72$ \\
$>3$ & 54 & 134 & 71 & 0.92 & $0.51 ; 1.65$ & $\mathrm{MH} \mathrm{c}^{2}: 6.63$ \\
$<4$ & 38 & 120 & 0.0 & & & $\mathrm{P}=0.010$ \\
$>4$ & 42 & 84 & 84 & 0.63 & $0.36 ; 1.10$ & $0.56<0.72<0.93$ \\
$<5$ & 53 & 155 & 0.0 & & & \\
$>5$ & 27 & 49 & 96 & 0.62 & $0.34 ; 1.13$ & \\
$<6$ & 58 & 162 & 0.2 & & & \\
$>6$ & 22 & 42 & 10 & 0.68 & $0.36 ; 1.30$ & \\
$<7$ & 68 & 185 & 0.1 & & & \\
$>7$ & 12 & 19 & 67 & 0.58 & $0.25 ; 1.35$ & \\
\hline
\end{tabular}

*MH: Mantel Haenszel, \#OR: odds ratio

Association between fever in the first year of life and atopy in children with or without family history of atopic disease

Analysis of fever episodes in the first year of life and atopy after stratifying the atopic disease history in the family showed that there was no statistically significant association. Fever episodes of more than seven times in the first year showed the smallest $\mathrm{P}$ value and odds ratio to atopy in the group of children with family history of atopic disease compared with children without family history of atopic disease. Generally, there were decreased odds ratio as fever episodes increase, but trend analyses showed no statistical significance $(\mathrm{P}=0.071)$ (Table 3$)$.

Association between fever episodes in the first year of life and atopy in children with atopic disease history in the family

There was no statistically significant association between fever episodes and atopy in children with family history of atopic disease. There was a decreased $\mathrm{OR}$ as fever episodes increase, except at point of six fever episodes. Trend analysis using Mantel Haenszel 
Susy P Wihadi et al : Fever and atopy in association with family history of atopic disease

test showed that this decrease was not statistically significant $(\mathrm{P}=0.77)$ (data not shown).

\section{Association between fever episodes in the first year of life and atopy in children without family history of atopic disease}

In children without family history of atopic disease there were statistically significant association between fever episodes in the first year of life and atopy starting at point more than four times of fever episodes $(\mathrm{P}=0.03, \mathrm{OR}=0.39$, CI 95\% 0.18;1.01) except at point $>6$ times of fever episodes $(\mathrm{P}=0.66$, $\mathrm{OR}=0.45$, CI 95\% 0.17;1.17). Table 4 also shows that the odds ratio is decreasing as fever episodes increase, except at point more than six times of fever

Table 3. Association between fever in the first year of life and atopy in children with or without family history of atopic disease

\begin{tabular}{ccccccc}
\hline $\begin{array}{c}\text { Fever } \\
\text { Episodes }\end{array}$ & + & - & Atopy & OR & Cl 95\% & \\
\hline$<1$ & 3 & 1 & & & & \\
$>1$ & 43 & 33 & 0.63 & 0.43 & $0.02 ; 5.06$ & \\
$<2$ & 5 & 5 & & & & \\
$>2$ & 41 & 29 & 0.73 & 1.41 & $0.32 ; 6.34$ & \\
$<3$ & 16 & 10 & & & & MH OR: 0.67 \\
$>3$ & 30 & 24 & 0.61 & 0.78 & $0.27 ; 2.25$ & MH c c $^{2} .27$ \\
$<4$ & 24 & 14 & & & & $\mathrm{P}=0.071$ \\
$>4$ & 22 & 20 & 0.33 & 0.64 & $0.24 ; 1.72$ & $0.43<0.67<1.03$ \\
$<5$ & 32 & 21 & & & & \\
$>5$ & 14 & 13 & 0.46 & 0.71 & $0.25 ; 1.99$ & \\
$<6$ & 35 & 23 & & & & \\
$>6$ & 11 & 11 & 0.4 & 0.66 & $0.22 ; 1.97$ & \\
$<7$ & 42 & 26 & & & & \\
$>7$ & 4 & 8 & 0.06 & 0.31 & $0.07 ; 1.30$ & \\
\hline
\end{tabular}

Table 4. Association between fever episodes in the first year of life and atopy in children with or without family history of atopic disease

\begin{tabular}{ccccccc}
\hline $\begin{array}{c}\text { Fever } \\
\text { Episodes }\end{array}$ & Atopy & $\begin{array}{c}\text { Non } \\
\text { atopy }\end{array}$ & P & OR & Cl 95\% & \\
\hline$<1$ & 1 & 7 & & & & \\
$>1$ & 33 & 101 & 0.68 & 0.44 & $0.02 ; 3.78$ & \\
$<2$ & 5 & 19 & & & & \\
$>2$ & 29 & 89 & 0.69 & 0.81 & $0.24 ; 2.57$ & \\
$<3$ & 10 & 40 & & & & MH OR: 0.48 \\
$>3$ & 24 & 68 & 0.41 & 0.71 & $0.28 ; 1.75$ & MH c $c^{2}: 15.72$ \\
$<4$ & 14 & 67 & & & & P<0.001 \\
$>4$ & 20 & 41 & 0.03 & 0.43 & $0.18 ; 1.01$ & $0.32<0.48<0.69$ \\
$<5$ & 21 & 87 & & & & \\
$>5$ & 13 & 21 & 0.02 & 0.39 & $0.16 ; 0.98$ & \\
$<6$ & 23 & 89 & & & & \\
$>6$ & 11 & 19 & 0.06 & 0.45 & $0.17 ; 1.17$ & \\
$<7$ & 26 & 100 & & & & \\
$>7$ & 8 & 8 & 0.02 & 0.26 & $0.08 ; 0.85$ & \\
\hline
\end{tabular}

episodes, trend analysis showed that decreased OR was statistically significant $(\mathrm{P}<0.001)$.

\section{Discussion}

Atopy in children was proved by skin prick test. Of 284 children there were $27.8 \%$ atopic children. There were $32.4 \%$ atopic children in group with family history of atopic disease and $23.9 \%$ in group without family history of atopic disease. Alford et al ${ }^{22}$ showed that the risk of being atopy in children with maternal history of atopic disease was $39.8 \%$, while in paternal history of atopic disease was $30.2 \%$, and if there were no family history of atopic disease the risk was $29 \%$. Koning et al23 mentioned that if one of the parents had the history of atopic disease, the risk of the child to become atopy was $20-40 \%$, if both of the parents had the history of atopic disease the risk was $60-80 \%$, if one of the siblings had the history of atopic disease the risk was $20-30 \%$, and if there were no atopic disease history in both parents the risk of being atopy was $10 \%$.

In this study the risk of being atopy was $52 \%$. It was higher in children with atopic disease history compared to that without atopic disease history but this difference was not significant $(\mathrm{P}=0.11)$.

The insignificant differences of nonatopy in children with and without family history of atopic disease and low number of atopy children in this study might be caused by the number of allergen.

This study used only eight allergens, so the negative result did not rule out the atopy especially in children with family history of atopic disease.

Fever is common in the first year of life, $51 \%$ fever episodes affected children with family history of atopic disease and 49\% in children without family history of atopic disease. Information regarding fever episodes in the first year of life was obtained based on parents report. This is one of the weaknesses of this study since the parents could not accurately report the number of fever episodes in the first year of life of their children. However, since the information was obtained in phase I, when the child age was between 15-18 months, we hope the recall bias could be minimized.

Generally there was no significant association between fever in the first year of life and atopy, but as fever episodes increased, the risk of being atopy decreased and trend analysis using Mantel Haenszel 
Susy P Wihadi et al: Fever and atopy in association with family history of atopic disease

showed statistical significance $(P=0.01)$. This revealed an inverse association between fever episodes in the first year of life and the risk of being atopy.

The association between fever in the first year of life and atopy in children based on the history of atopic disease was not significant, but in this group there was a decreased risk of being atopy as fever episodes increased, even though this risk was not significant either $(\mathrm{P}=0.07)$. This unsignificant difference might be due to the sample size and inaccurate information regarding fever episodes.

In children with family history of atopic disease, there was no significant association between fever and atopy, although there were decreased risk but trend analysis showed that it was not significant $(\mathrm{P}=0.77)$. This showed that cumulative fever episodes were not related to atopy in children with family history of atopic disease. Atopy were influenced not only by genetic factor but environmental factors which are multifactorial such as allergen sensitization, number of siblings, hygiene, infection, antibiotic use in the first two years of life, vaccination, and breast feeding. 24,25 In children with family history of atopic disease there were genetic factor of being atopy, so the development of immune response in these children skewed to Th2 cell subtype. In the first two years of life, the window period, this skew could be modulated by environmental factors, in that case, the development could be driven to Th1 cell subtype. ${ }^{26}$ In this study, we only analyzed one of the environment factors, the others, such as antibiotic course, immunization coverage, helminth infestation, and breast feeding were not adjusted to atopy (they will be published elsewhere), so the unsignificant result of this study was probably due to other factors which have bigger effect to atopy. This would be another weakness of this study.

Analysis in children without family history of atopic disease showed a significant association between fever and atopy that began at point more than four times of fever episodes $(\mathrm{P}=0.03, \mathrm{OR}=0.39$, CI 95\% $0.18 ; 1.01)$. At point more than six times of fever episodes there was no significant association with atopy $(\mathrm{P}=0.66)$ and there was an increased risk $(\mathrm{OR}=0.45$, CI $95 \%$ 0.17; 1.17). At point more than times of fever episodes there was significant association and decreased risk. This might due to the pattern of fever episodes, where the number of children who had six times of fever episode was bigger than those with five and seven episodes. Trend analysis showed that the decreased risk was significant $(\mathrm{P}<0.001)$. This implicate that increasing fever episodes in the first year of life was a protective factor to atopy.

In a cross sectional study, von Mutius et al ${ }^{19}$ showed that fever episodes in the first year of life have a strong association with asthma and wheezing in school age children especially in nonatopy children. Within asthmatic children, the number of fever episodes were strongly inversely related to the prevalence of atopy $(\mathrm{OR}=0.25$, CI 95\% 0.11;0.54 for skin prick test). Williams et $a^{21}$ showed that children with fever before age one year were inversely associated with the risk of allergic sensitization by age six to seven years and the effect was dose dependent. More frequent the fever episodes, the risk of being atopy or seroatopy would be smaller $(\mathrm{P}=0.02)$.

Infections are the most common cause of fever in young children. ${ }^{18}$ Fever is induced by both exogenous pyrogens, like lipopolysaccharide and endogenous pyrogenic cytokine most notably interleukin (IL)-1, IL6 , and tumor necrosis factor (TNF), that induce the production of prostaglandin E2 in the preoptic area: this mediator stimulates the neural pathways that raise body temperature. It is known that the elevated body temperature enhances both the inflammatory response and the immune function. Temperature elevation appears to be primarily affect the phase of recognition and sensitization or activation of mononuclear leukocytes and induces cell proliferation and enhances interferon (IFN) $-\gamma$ secretion. These findings suggest that fever may induce a Th1 response. Moreover, fever is subject to endogenous inhibitory processes via a variety of specific inhibitory mechanisms, such as the IL-1 antagonist (IL$1 \mathrm{ra})$. It has recently been found that IL-1 ra blocks Th2 but not Th1 clonal proliferation. ${ }^{26}$ Yazdanbakhsh et al2 proposed a hypothesis which suggested that repeated stimulation of the immune system results in a regulatory network of dendritic cells and $T$ cells that down regulate allergic response through the production of TGF- $\beta$ and IL-10. Therefore, if fever indicates periods of intense immune stimulation, each episode would be expected to reduce the likelihood of the development of allergic sensitization.

The next question is why fever protects from the development of atopy only in children without atopic disease history in the family? It has recently been shown that children with atopic disease history may develop a strong, Th2 skewed immune response, therefore, fever 
Susy P Wihadi et al : Fever and atopy in association with family history of atopic disease

episodes may be ineffective in protecting children with already skewed Th2 immune responses. ${ }^{20,28}$

In conclusion, this study suggests that fever in the first year of life is a protective factor of being atopy in children without family history of atopic disease if fever reveals before atopy manifested.

\section{References}

1. Beasley R, Crane J, Lai C, Pearce N. Prevalence and etiology of asthma. J Allergy Clin Immunol 2000; 105:S466-72.

2. Wang XS, Goh DYT, Shek LPC, Baratawidjaja K, Darwis A, Kartasasmita C, et al. Affluence and asthma, evidence from South East Asia. Allergy \& Clin Immunol International. J World Allergy Organization 2005;17:53-7.

3. Sundaru H. Perbandingan prevalensi dan derajat berat asma antara daerah urban dan rural pada siswa sekolah usia 13-14 tahun. Disertasi. Jakarta: Universitas Indonesia; 2005.

4. Strachan DP. Hay fever, hygiene and household size. BMJ 1989;299:1259-60.

5. Matricardi PM, Franzinelli F, Franco A, Caprio G, Murru F, Cioffi D, et al. Sibship size, birth order, and in 11.371 Italian young men. J Allergy Clin Immunol 1998;101:439-44.

6. Romagnani S. Immunologic influences on allergy and the Th1/ Th2 balance. J Allergy Clin Immunol 2004;113:395-400.

7. Svanes C, Jarvis D, Chinn S, Burney P. Childhood environment and adult: results from the European Community Respiratory Health Survey. J Allergy Clin Immunol 1999:103:415-20.

8. Krämer U, Heinrich J, Wjst M, Wichmann HE. Age of entry to day nursery and allergy in later childhood. Lancet 1998;352:450-4

9. Ball TM, Castro-Rodriguez J, Griffith KA, Holberg CJ, Martinez FD, Wright AL. Siblings, day-care attendance, and the risk of asthma and wheezing during childhood. N Engl J Med 2000;343:538-43.

10. Shaheen SO, Aaby P, Hall AJ, Barker DJP, Heyes CB, Shiell AW. Measles and atopy in Guinea-Bissau". Lancet 1996;347:1792-6.

11. Alm JS, Swartz J, Lilja G, Scheynius A, Pershagen G. Atopy in children of families with an anthroposophic lifestyle. Lancet 1999;353:1485-8.

12. Martinez FD, Stern DA, Wright AL, Taussig LM, Halonen M. Association of non-wheezing lower respiratory tract illnesses in early life with persistently diminished serum IgE levels. Thorax 1995;50:1067-72.

13. Faroqi IS, Hopkin JM. Early childhood infection and atopic disorder. Thorax 1998;53:927-32.
14. Ponsonby AL, Couper D, Dwyer T, Carmichael A, Kemp A. Relationship between early life respiratory illness, family size over time, and the development of asthma and hay fever: a seven year follow up study. Thorax 1999;54:664-9.

15. McKeever T, Lewis SA, Smith C, Collins J, Heatlie H, Frischer $\mathrm{M}$, et al. Early exposure to infections and antibiotics and the incidence of allergic disease: a birth cohort study with the West Midlands General Practice Research Database. J Allergy Clin Immunol 2002;109: 43-50.

16. Bager P, Westergaard T, Kostgaard K, Hjalgrim H, Melbye M. Age at childhood infections and risk of atopy. Thorax 2002;57:379-82.

17. Njå F, Nystad W, Hetlevik O, Carlsen KCL, Carlsen KH. Airway infection in infancy and the presence of allergy and asthma in school age children. Arch Dis Child 2003;88:566-9.

18. McCarthy PL. Fever in infants and children. In: Mackowiak PA, editor. Fever, basic mechanisms and management. Philadelphia: Lippincot-Raven Publishers; 1997. p. 351-62.

19. Von Mutius E, Illi S, Hirsch T, Leupold W, Keil U, Weiland SK. Frequency of infections and risk of asthma, and airway hyperresponssiveness in children. Eur Respir J 1999;14:4-11.

20. Calvani M, Alessandri C, Bonci E. Fever episodes in early life and the development of atopy in children with asthma. Eur Respir J 2002;20:391-6.

21. Williams LK, Peterson EL, Ownby DR, Johnson CC. The relationship between early fever and allergic sensitization at age 6-7 years. J Allergy Clin Immunol 2004;113:291-6.

22. Alford HS, Zoratti E, Peterson EL, Maliarik M, Ownby DR, Johnson CC. Parental history of atopic disease: Disease pattern and risk of pediatric in offspring. J Allergy Clin Immunol 2004;114: 1046-50.

23. Koning H, Baert MRM, Oranje AP, Savelkoul HFJ, Neijens HJ. Development of immune functions, related to allergic mechanism, in young children. Pediatric Research 1996; 40:36375.

24. Kay AB. Allergy and allergic diseases. N Engl J Med 2001;344(1):30-7.

25. Savelkoul HFJ, Neijens HJ. Immune responsses during allergic sensitization and the development of atopy. Allergy 2000;55:989-97.

26. Roberts NJ. Impact of temperature elevation on immunologic defenses. Rev Infect Dis 1991;13:462-72.

27. Yazdanbakhsh M, Kremsner PG, van Ree R. Allergy, parasites, and the hygienne hypothesis. Science 2002;296:490-4.

28. Renzi PM, Turgeon JP, Yang JP. Cellular immunity is activated and a Th-2 response is associated with early wheezing in infants after bronchiolitis. Pediatrics 1997;130:584-93. 